\title{
Geociências
}

\section{Propriedades reológicas de matérias-primas do Pólo Cerâmico de Santa Gertrudes provenientes da Formação Corumbataí (região de Rio Claro, SP)}

\author{
(Rheological properties of the raw material used in the Santa \\ Gertrudes Ceramic Cluster proceeding from the Corumbataí \\ Formation located in the Rio Claro, SP area)
}

\author{
Ana Candida de Almeida Prado, Carolina Del Roveri, Rogers Raphael Rocha \\ Pós-graduandos em Geologia Regional - IGCE - UNESP - Rio Claro-SP \\ E-mail: acaprado@gmail.com, cdroveri@rc.unesp.br, roger@rochaforte.com.br \\ Antenor Zanardo, Maria Margarita Torres Moreno \\ Professores, Doutores, DPM, IGCE, UNESP, Rio Claro-SP \\ E-mail: azanardo@rc.unesp.br, mmoreno@rc.unesp.br \\ José Francisco Marciano Motta \\ Pesquisador - IPT, São Paulo-SP. E-mail: jfmotta@ipt.br \\ Ana Paula Margarido Menegazzo \\ Gerente - CITEC - CCB, Santa Gertrudes-SP.E-mail: anapaula.ccb@terra.com.br
}

\section{Resumo}

Siltitos e argilitos da Formação Corumbataí são fontes de matéria-prima para a indústria cerâmica do Pólo de Santa Gertrudes. Litotipos provenientes de três minas (Tute, Granusso e Cruzeiro), localizadas na região de Rio Claro - SP, foram caracterizados quanto à curva de defloculação, conteúdo crítico de sólidos e tempo de envelhecimento (propriedades reológicas). Os litotipos representam desde a base até o topo da coluna estratigráfica dessa formação. Os resultados reológicos foram correlacionados com a composição mineralógica. Os representantes da base estratigráfica apresentaram boa defloculação, quase não necessitando adicionar defloculante, e, de forma geral, continham illita, feldspato, quartzo, hematita, clorita e interestraficados de clorita - argilomineral expansivo ou de illita argilomineral expansivo. A maioria dos litotipos do topo defloculou, porém a quantidade ideal de defloculante foi superior aos adicionados às amostras da base. Os litotipos do topo continham carbonatos, além dos minerais supracitados. Uma amostra coletada no topo da mina Tute, com sinais evidentes de intemperismo, não defloculou. Os carbonatos presentes nos estratos superiores da formação e a alteração supérgena prejudicaram a defloculação. A quantidade máxima de sólidos na barbotina foi $66 \%$ em peso para os litotipos do topo da formação. Os litotipos testados apresentaram o fenômeno de envelhecimento da suspensão, porém as barbotinas, após 120 horas de seus preparos, ainda apresentavam viscosidades semelhantes àquelas usadas pela indústria de placas cerâmicas para revestimento.

Palavras-chave: Argilas, defloculação, composição mineralógica, reologia, Formação Corumbataí, placas cerâmicas para revestimento.

\begin{abstract}
Siltstones and mudstones from the Corumbataí Formation are exploted as raw material for the ceramic industries of Santa Gertrudes'Cluster. Lithotypes from three quarries (Granusso, Tute and Cruzeiro), located in the Rio Claro region - SP Brazil, were characterized rheologically (deflocculation curve, solid critic content and aging time), representing the entire stratigraphic column of this formation. The results obtained were correlated with the mineralogical composition. The lithotypes in the lower part of the formation deflocculated very well, with small doses of deflocculant, and were generally composed of illite, feldspar, quartz, hematite, chlorite, and interstratified (chlorite together with expansive clay minerals or illite together with expansive clay minerals). The majority of the lithotypes found at the top of the formation deflocculated. However, for this to occur, a greater amount of deflocculant was necessary, in comparison to the amount used for the bottom samples. The lithotypes found at the upper part contained the same minerals as the bottom, but in addition, carbonates were found. One of the samples, collected at the top of Tute quarry showed evidences of weathering and did not deflocculate. The carbonates at the top strata and the supergenic alteration damaged the deflocculation. The maximum amount of solids in the suspension was $66 \%$ in weight for the lithotypes from the top. The test samples presented characteristics of suspension aging, however after 120 hours their viscosity was similar to that used in the tile industry.
\end{abstract}

Keywords: Clays, deflocculation, mineralogical composition, rheology, Corumbataí Formation, ceramic tiles. 
Propriedades reológicas de matérias-primas do Pólo Cerâmico de Santa Gertrudes provenientes...

\section{Introdução}

A Formação Corumbataí é uma unidade da bacia Sedimentar do Paraná, de idade permiana (Landim, 1970) e é composta por siltitos e argilitos. Praticamente toda a formação é fonte de matériaprima para as indústrias de placa cerâmica para revestimento da região de Santa Gertrudes, no Estado de São Paulo. O pólo formado por essas indústrias é o principal produtor de placas cerâmicas para revestimento do Brasil.

A moagem é a etapa inicial, dentro do processo de produção cerâmico, na fabricação de revestimentos. Basicamente, a moagem reduz os tamanhos das partículas e homogeneíza os diversos materiais presentes na massa cerâmica. A grande maioria das fábricas do Pólo de Santa Gertrudes mói a matéria-prima pelo processo a seco. Porém a moagem a úmido é mais eficaz em reduzir o tamanho das partículas e a posterior secagem pelo processo de atomização gera um pó que preenche o molde mais eficazmente do que os pós obtidos por moagem a seco. O menor tamanho de partícula e o preenchimento mais eficaz do molde acarretam maiores valores de resistência mecânica da peça seca, intervalos de queima mais amplos com temperaturas menores e menor susceptibilidade à deformação piroplástica, caso as propriedades das peças cruas sejam iguais (Amorós et alii, 1988; Amorós et alii, 1990).

Até o final dos anos 90, existia, entre os ceramistas do pólo, a idéia de que o material da Formação Corumbataí não dispersava em meio aquoso, isto é, não defloculava, devido aos resultados dos primeiros ensaios realizados nas indústrias. Isto ocorreu, provavelmente, porque utilizaram argilas do topo da Formação, geralmente materiais mais alterados, com maior desequilíbrio de cargas superficiais, o que dificultou a defloculação. Em estudos mais recentes, argilas mais sãs deflocularam bem (Thomazella et alii, 2000; Roveri \& Zanardo, 2003; Coutinho Júnior, 2005; Prado et alii, 2006).

Esse trabalho reporta os resultados de estudos de propriedades reológicas de amostras selecionadas em três minas gião de Rio Claro, a saber: mina Tute, mina Cruzeiro e mina Granusso. Nas minas Tute e Cruzeiro, caracterizou-se a reologia de materiais provenientes de perfis. Na mina Granusso testaram-se duas amostras para comparação com amostras da mina Cruzeiro, todas localizadas em uma mesma seqüência estratigráfica.

As amostras foram escolhidas buscando representar os principais litotipos explotados nas minas que abastecem o Pólo Cerâmico de Santa Gertrudes, bem como seu posicionamento estratigráfico. A Figura 1 apresenta a localização geográfica das três minas. do Pólo Cerâmico Santa Gertrudes, re-

\section{Materiais e métodos}

Cinco amostras da mina Tute, locada nos níveis do topo da Formação Corumbataí, foram coletadas na forma de amostras de calha. Outros dez litotipos foram coletados em minas que explotam a base da formação: dois na mina Granusso e oito na Cruzeiro. Foram coletados aproximadamente vinte quilos de cada uma das amostras.

As minas Cruzeiro e Granusso representam a porção basal da Formação Corumbataí, expondo cerca de 40 metros de diversos litotipos: siltitos maciços, intercalados com bandas arenosas, material rico em carbonato, cortado por veios de quartzo e calcita.

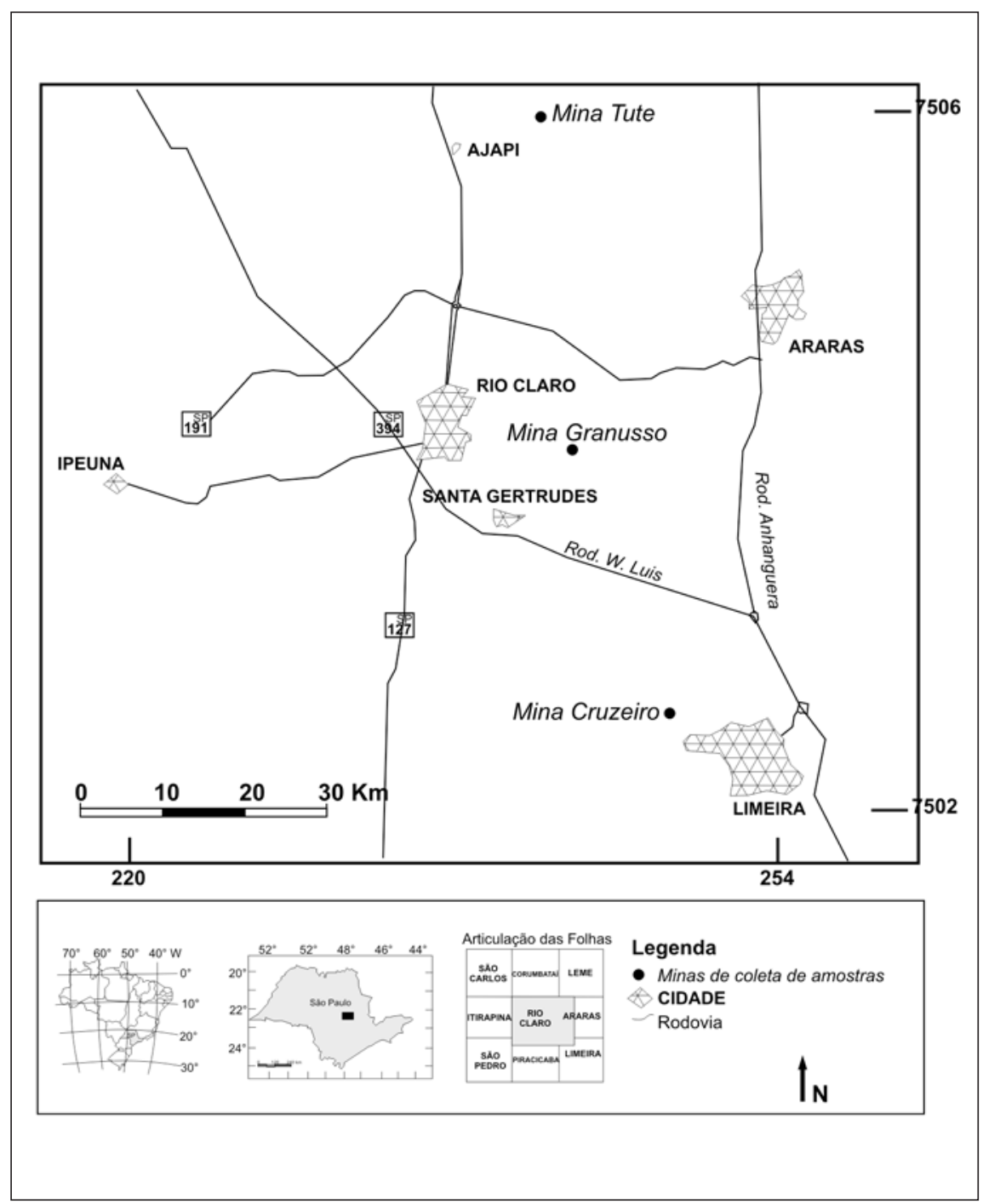

Figura 1 - Localização das minas estudadas (modificado de Christofoletti, 2003). 
O contato concordante da Formação (Fm.) Corumbataí com a formação inferior (Fm. Irati) está exposto na mina Cruzeiro. Em ambas as formações, há corpos básicos, associados à Formação Serra Geral, intrudidos de forma concordante e discordante (soleiras e diques).

Os litotipos amostrados nesse estudo na mina Cruzeiro estão localizados a 8 metros acima do contato com a Fm. Irati. A mina Granusso apresenta uma bancada de 22 metros. A Figura 2 esquematiza a localização dessas amostras e das amostras advindas da mina Tute.

A coleta de material na mina Cruzeiro foi feita por meio de furos por sondagem a percussão, resultando em cinco amostras, correspondentes a cada uma das bancadas, da base para o topo da mina: CB2, CB3, CB4, CB5 e CB6. A bancada 1 dessa mina não foi amostrada, pois não é utilizada para fins cerâmicos. A bancada 1 apresenta, em sua parte inferior, a transição da Formação Irati para a Formação Corumbataí e, em sua parte superior, um siltito esverdeado bastante duro. Também há diferenças de granulometria, cor e diagênese na direção horizontal, sendo que a bancada 3 foi escolhida para caracterizar essa variação por meio da coleta de três amostras: CB3a, CB3b e CB3c, distantes, aproximadamente, 40 metros uma da outra.

Os litotipos da base da mina Granusso foram representados por duas amostras: G1 (parte inferior) maciça de coloração roxa e, logo acima, G2, que apresenta estrutura variegada muito parecida com a amostra CB3b da mina Cruzeiro.

Um perfil da principal frente de lavra da mina Tute resultou na coleta de quatro amostras: TB1, TB2, TB3, TB4, representando, respectivamente, da base para o topo da mina, a bancada 1 , bancada 2, bancada 3 e bancada 4. Uma amostra adicional TPátio representa a mistura das quatro bancadas, após beneficiamento. TPátio é composta por, aproximadamente, 20, 45, 20 e 15\% de TB1, TB2, TB3 e TB4, respectivamente, conforme a configuração das bancadas da mina, pois, nessa mina, a altura da bancada é proporcional ao percentual de material utilizado na mistura.

Os materiais foram analisados no Labcer/IGCE/UNESP por difração de raios $\mathrm{X}$, por meio de amostras totais e fração fina (difratômetro da marca Siemens D5000, medidas com radiação Co - comprimento de onda $=1,7893 \AA$, passo de 0,05 graus e tempo de exposição de 0,8 s para cada passo). Para a realização das análises mineralógicas das frações finas, as amostras passaram por separação granulométrica através do processo de decantação. A parte mais fina foi selecionada e duas lâminas foram preparadas. Uma dessas lâminas foi amostrada na forma natural e depois deixada em atmosfera de etileno-glicol por $24 \mathrm{~h}$ e a segunda, aquecida a $500^{\circ} \mathrm{C}$ por 2 horas.

A barbotina, suspensão composta por argila mais água, foi preparada com $34 \%$ de água deionizada e $66 \%$ em peso de argila (densidade da barbotina igual $\left.1,70 \mathrm{~g} / \mathrm{cm}^{3}\right)$. Essa mistura foi homogeneizada e moída por quatro minutos em moinho periquito. As viscosidades fo-

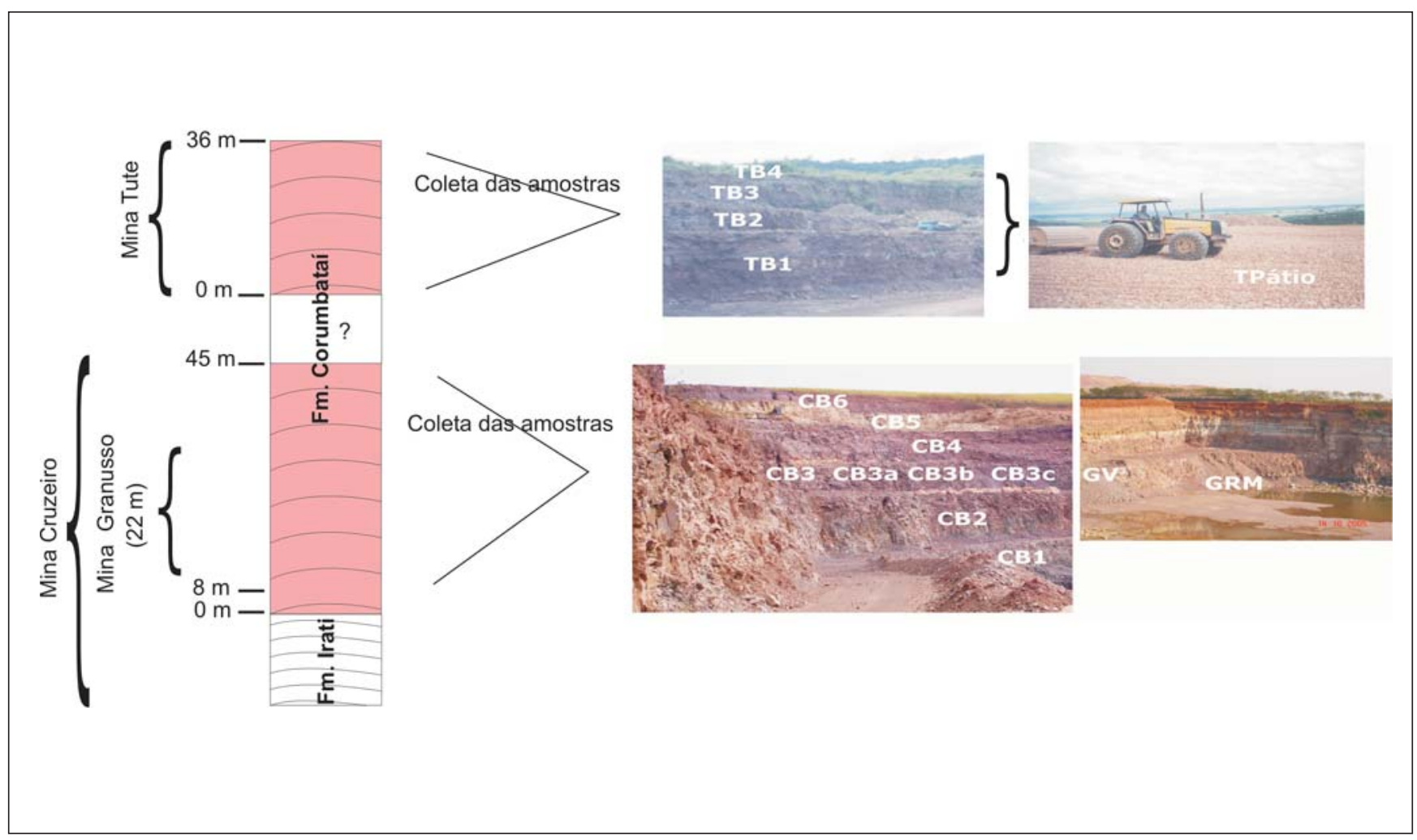

Figura 2 - Esquema da coluna estratigráfica da Fm. Corumbataí, com as posições de coleta das amostras nas minas estudadas (sem escala). 
Propriedades reológicas de matérias-primas do Pólo Cerâmico de Santa Gertrudes provenientes...

ram medidas em viscosímetro Brookfield variando a quantidade do defloculante (silicato de sódio). A temperatura e a quantidade de partículas grossas da barbotina foram controladas, pois, reconhecidamente, esses dois parâmetros afetam a viscosidade. A porcentagem de partículas, em peso, de tamanho superior a $74 \mu \mathrm{m}$ (determinada por meio de peneiramento a úmido em malha ABNT 200) sempre foi inferior a $5 \%$. E a temperatura variou entre 21 e $25^{\circ} \mathrm{C}$.

Alguns testes adicionais foram realizados, ora em amostras da mina Tute, ora das minas Cruzeiro e Granusso, buscando comparar amostras posicionadas em uma mesma seqüência estratigráfica. Essa divisão considerou que a mina Tute está posicionada no topo estratigráfico da Formação Corumbataí, enquanto que as minas Cruzeiro e Granusso representam a base da formação.

Como ensaios adicionais nas amostras da mina Tute, avaliaram-se a concentração crítica de sólidos e a variação da viscosidade com o tempo de moagem. O ensaio de concentração crítica de sólidos mediu a variação da viscosidade à medida que se diluiu a barbotina, sendo que esta já continha determinada quantidade de defloculante apropriada para sua defloculação.

A variação da viscosidade com o tempo, após o preparo da barbotina, foi determinada nas amostras da mina Granusso (G1 e G2) e em CB3a, Cb3b e CB3c (mina Cruzeiro). A barbotina foi agitada continuamente nas primeiras 6 horas, depois deixada em repouso, e, após 24, 48, 72, 96 e 120 horas, mediram-se a viscosidade e o $\mathrm{pH}$ desta em repouso e depois de agitada por dois minutos.

\section{Resultados e discussões}

Os minerais identificados por difração de raios $X$ estão relacionados na Tabela 1. Zanardo (2003) verificou que as principais fases minerais que compõem os argilitos/siltitos da Formação Corumbataí em ordem decrescente de abundância são: illita, quartzo, feldspa- tos alcalinos, hematita, carbonatos, cloritas, filossilicatos interestratificados, montmorillonitas, restos fósseis, biotita, muscovita, hidróxidos de ferro, analcima e caulinita. Variações composicionais são evidentes, principalmente na direção vertical, ocorrendo diferenças nas propriedades cerâmicas entre os materiais de minas locadas no topo e da base da formação (Roveri et alii, 2006). Portanto os minerais encontrados nesse trabalho são os mais comuns na formação e corroboram com a bibliografia específica.

Tabela 1 - Mineralogia das amostras estudadas determinada por meio de difratometria de raios $X(--=$ ausente; $x=$ presente $)$.

\begin{tabular}{|c|c|c|c|c|c|c|c|c|c|}
\hline \multirow[b]{2}{*}{ Amostra } & \multicolumn{9}{|c|}{ Minerais } \\
\hline & I & Mt & $\mathrm{Cl}$ & Inter & Qz & $A b$ & $\begin{array}{c}\text { Hm/outros } \\
\text { minerais } \\
\text { de Fe }\end{array}$ & Cal & Dol \\
\hline CB2 & $x$ & -- & $x$ & -- & $x$ & $x$ & $x$ & -- & -- \\
\hline CB3 & $x$ & -- & $x$ & -- & $x$ & $x$ & $x$ & -- & -- \\
\hline CB3a & $x$ & $x$ & $x$ & -- & $x$ & $x$ & $x$ & -- & -- \\
\hline CB3b & $x$ & -- & $x$ & -- & $x$ & $x$ & $x$ & -- & -- \\
\hline CB3C & $x$ & -- & $x$ & -- & $x$ & $x$ & $x$ & -- & -- \\
\hline CB4 & $x$ & -- & -- & $x$ & $x$ & $x$ & $x$ & $x$ & $x$ \\
\hline CB5 & $x$ & -- & $x$ & $x$ & $x$ & $x$ & $x$ & -- & $x$ \\
\hline CB6 & $x$ & $x$ & -- & -- & $x$ & $x$ & $x$ & $x$ & $x$ \\
\hline G1 & $x$ & -- & -- & -- & $x$ & $x$ & $x$ & -- & -- \\
\hline G2 & $x$ & -- & $x$ & -- & $x$ & $x$ & $x$ & -- & -- \\
\hline TB1 & $x$ & -- & -- & $x$ & $x$ & $x$ & $x$ & $x$ & -- \\
\hline TB2 & $x$ & -- & -- & $x$ & $x$ & $x$ & $x$ & $x$ & -- \\
\hline TB3 & $x$ & -- & -- & $x$ & $x$ & $x$ & $x$ & $x$ & -- \\
\hline TB4 & $x$ & -- & -- & $x$ & $x$ & $x$ & $x$ & $x$ & -- \\
\hline TPátio & $x$ & -- & -- & $x$ & $x$ & $x$ & $x$ & $x$ & -- \\
\hline
\end{tabular}

I = illita; $\mathrm{Mt}=$ montmorillonita; $\mathrm{Cl}$ = clorita; Inter = interestratificado de clorita/ argilomineral expansivo de distância interplanar principal a $14 \AA ̊$ ou interestratificado de illita/argilomineral expansivo de distância interplanar principal a $14 \AA$; $\mathrm{Qz}=$ quartzo; $\mathrm{Ab}=$ albita; $\mathrm{Hm}$ = hematita; Cal = calcita; Dol = dolomita.

Amostras CB2, CB3, CB3a, CB3b, CB3c, CB4, CB5 e CB6 = Mina Cruzeiro; G1 e G2 = Mina Granusso; TB1, TB2, TB3, TB4 e TPátio = Mina Tute. 
Ana Candida de Almeida Prado et al.

pal a $14 \AA ̊$ ou de illita - argilominerais expansivos de distância interplanar principal a $14 \AA$ estão presentes nas amostras (CB4 e CB5) do topo da mina; a quantidade de feldspato aumenta em direção ao topo até CB5 depois torna a diminuir; CB3b contém maior teor de albita e quartzo e CB3a apresenta montmorillonita.

- As amostras da mina Granusso são mineralogicamente parecidas com CB2 e com as amostras da bancada 3 da Cruzeiro (exceto pela ausência de clorita em G1); a quantidade de quartzo e albita de G2 é superior à de G1.

- Para as amostras da mina Tute, observou-se que da base para o topo, de TB1 até TB3, o teor de illita diminui e, por outro lado, o de calcita, albita e de argilominerais interestratificados aumenta; tanto a clorita como os interestratificados estão presentes como minerais acessórios, pois essas fases só foram identificadas na análise difratométrica da fração fina; o difratograma de TB4 é semelhante ao de TB3, no que diz respeito às fases minerais, porém é provável que as quantidades das fases minerais sejam diferentes nas duas bancadas, uma vez que TB4 localiza-se na porção superior da mina (maior percolação de água atual) e, na análise de campo, observaram-se evidentes sinais de intemperismo, que aumenta para o topo (pedogênese), com nítida lixiviação de carbonatos; TPátio apresenta comportamento médio entre todas as bancadas.

Um trabalho que caracterizou as mesmas amostras da mina Tute (Roveri, 2005) determinou que o teor de carbonato em TB3 é aproximadamente 15\% e, conforme observações de campo, este ocorre disseminado na rocha sob a forma de matriz (testada com ácido clorídrico a $10 \%$ ) ou de cristais poiquilotípicos (milimétricos a centimétricos).

A análise mineralógica permite dividir as amostras em dois grandes grupos: as advindas da mina Tute, que apresentam carbonatos; e as da mina Cruzeiro e Granusso, que apresentam litotipos com menor ou pouquíssimo carbonato.
A Figura 3 mostra as curvas de defloculação das amostras. Para as amostras da mina Cruzeiro, foram feitas as seguintes observações:

- A barbotina de CB2 era bem fluida e aderiu muito pouco nas bordas do recipiente, porém sedimentou tão rapidamente que mesmo em agitação foi impossível medir a viscosidade. Em repouso, havia as seguintes fases separadas: película de espuma e pontos de cor preta de matéria orgânica na superfície; suspensão de cor marrom clara; material sedimentado de cor mais escura e rígido.

- O consumo de defloculante e a viscosidade aumentam da base para o topo da mina Cruzeiro.

- Na medida realizada na amostra CB6, houve uma variação grande da tixotropia (capacidade de uma substância diminuir sua viscosidade com o tempo, quando é submetida a um esforço de cisalhamento constante, se o esforço é interrompido, a viscosidade da substância aumenta até o valor inicial) e o material ficou preso dentro do recipiente.

- A amostra CB3a se destaca pelo seu menor consumo de defloculante e menor viscosidade, o que aparentemente seria incoerente, pois a montmorillonita que está presente em CB3a geraria um maior consumo de defloculante (Barba et alii, 1997; Norton, 1979). Porém, segundo Souza Santos (1989), a montmorillonita muito fina e a matéria orgânica podem revestir as camadas argilosas modificando suas cargas superficiais e, assim, auxiliar a defloculação. Prado et alii (2006) concluíram que o litotipo CB3a continha maior teor de matéria orgânica do que CB3b e CB3c. Portanto, é possível que a montmorillonita e a matéria orgânica de CB3a auxiliaram sua defloculação.

Os menores percentuais de silicato de sódio e viscosidades nos pontos mais adequados da curva de defloculação são das amostras da mina Granusso, sendo que não foi necessário adicionar defloculante à amostra G2. Uma camada superficial negra flotou na barbotina de G2, trata-se de matéria orgânica que queima entre 550 e $600^{\circ} \mathrm{C}$. A matéria orgânica presente em quantidade relativamente alta em G2 também auxiliou sua defloculação.

A presença de carbonatos, liberando íons bivalentes $\left(\mathrm{Ca}^{+2} \mathrm{e} \mathrm{Mg}^{+2}\right)$, aumenta as forças de atração das partículas de argila (Souza Santos, 1989). Assim, a quantidade de defloculante ideal e a viscosidade nesse ponto para os litotipos da mina Tute são maiores do que para os outros litotipos.

Apesar do alto teor de carbonatos presentes nos litotipos da mina Tute, as amostras das bancadas TB1, TB2, TB3 e TPátio diminuíram suas viscosidades a valores trabalháveis na indústria cerâmica, para tanto foi necessário adicionar silicato de sódio em percentuais em relação à massa de material seco. Tais percentuais variaram entre $0,3 \%$ e $0,6 \%$, dependendo da amostra. Por estar a amostra TB4 fortemente lixiviada, seus componentes argilosos estão eletronicamente desequilibrados, assim a presença de íons em solução dificultou a defloculação (Roveri, 2005).

\subsection{Concentração crítica de sólidos}

Nesse ensaio (Figura 4), observouse que as amostras provenientes da Mina Tute chegaram a concentrações em torno de $66 \%$ em peso com viscosidades na faixa de 1000 cP. A amostra TB4 apresentou os piores resultados, com viscosidades elevadíssimas (superiores a 3000 cP) e alto teor de defloculante.

As amostras TPátio e TB2 suportaram um maior conteúdo de sólidos; a viscosidade de TB4 aumentou radicalmente ao elevar a concentração de sólidos de 65 para 67\%; TB1 e TB3 aumentaram suas viscosidades com um conteúdo relativamente baixo de sólidos.

\subsection{Variação da viscosidade com o tempo de moagem}

Maior tempo de moagem gera um maior número de partículas finas, que, uma vez desequilibradas eletronica- 


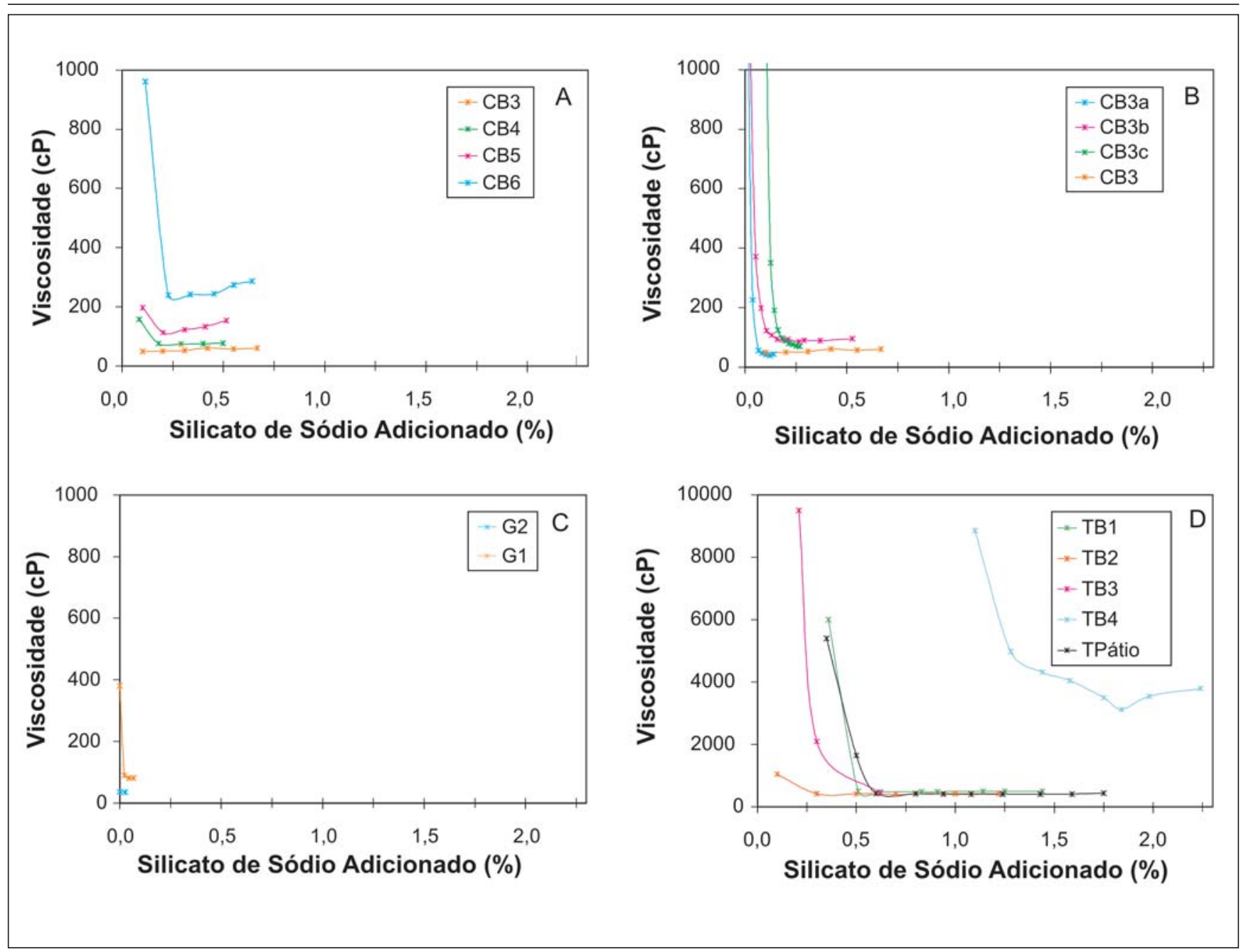

Figura 3 - Curvas de defloculação das amostras de: (a) mina Cruzeiro, perfil de CB2 (base) a CB6 (topo); (b) bancada 3 da mina Cruzeiro, variação horizontal; (c) mina Granusso; (d) mina Tute. Teor adicionado de silicato de sódio em \% peso. A escala da abscissa do gráfico 2.d. é 10 vezes maior do que as dos outros.

mente, tendem a formar aglomerados, o que aumenta a viscosidade do sistema (Krauskopf, 1972). Cinco minutos de moagem a mais no moinho periquito resultou em um aumento de viscosidade de 100cP em TPátio, porém TB2 não alterou sua viscosidade com o tempo de moagem, provavelmente por sua composição ser mais equilibrada entre os materiais plásticos (argilominerais) e os não plásticos (quartzo, feldspatos, carbonatos) (Figura 5).

\subsection{Variação da viscosidade com o tempo de preparo da barbotina}

As viscosidades das amostras CB3a e G2 permaneceram aproximadamente constantes e de CB3b, CB3c e G1 diminuíram ligeiramente nas primeiras 6 horas de ensaio (tixotropia). A viscosidade dos litotipos em repouso aumentou progressivamente com o passar do tempo, mas com agitação por somente

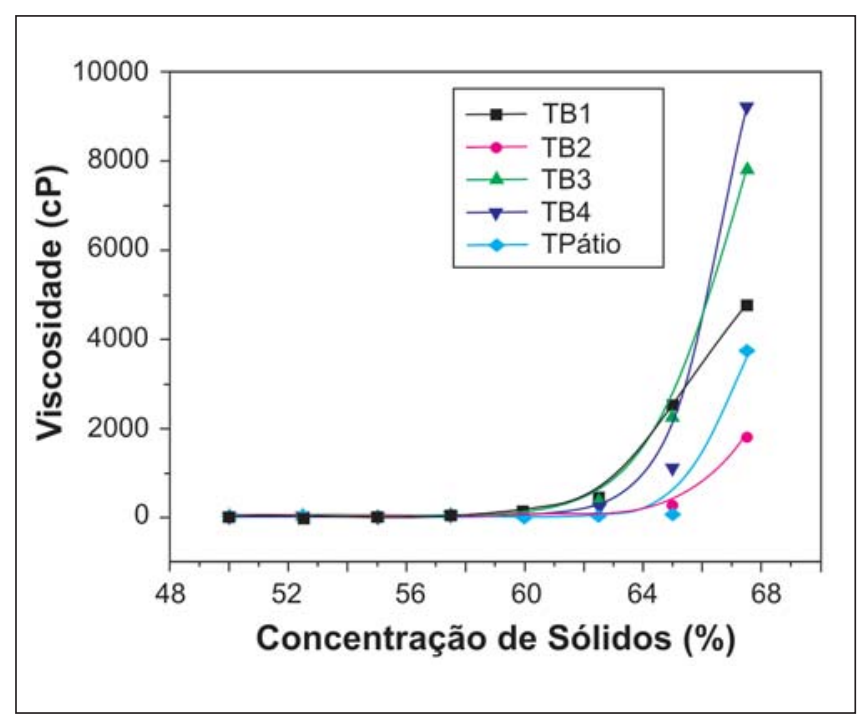

Figura 4 - Curva de concentração crítica de sólidos para amostras da mina Tute. 
Ana Candida de Almeida Prado et al.

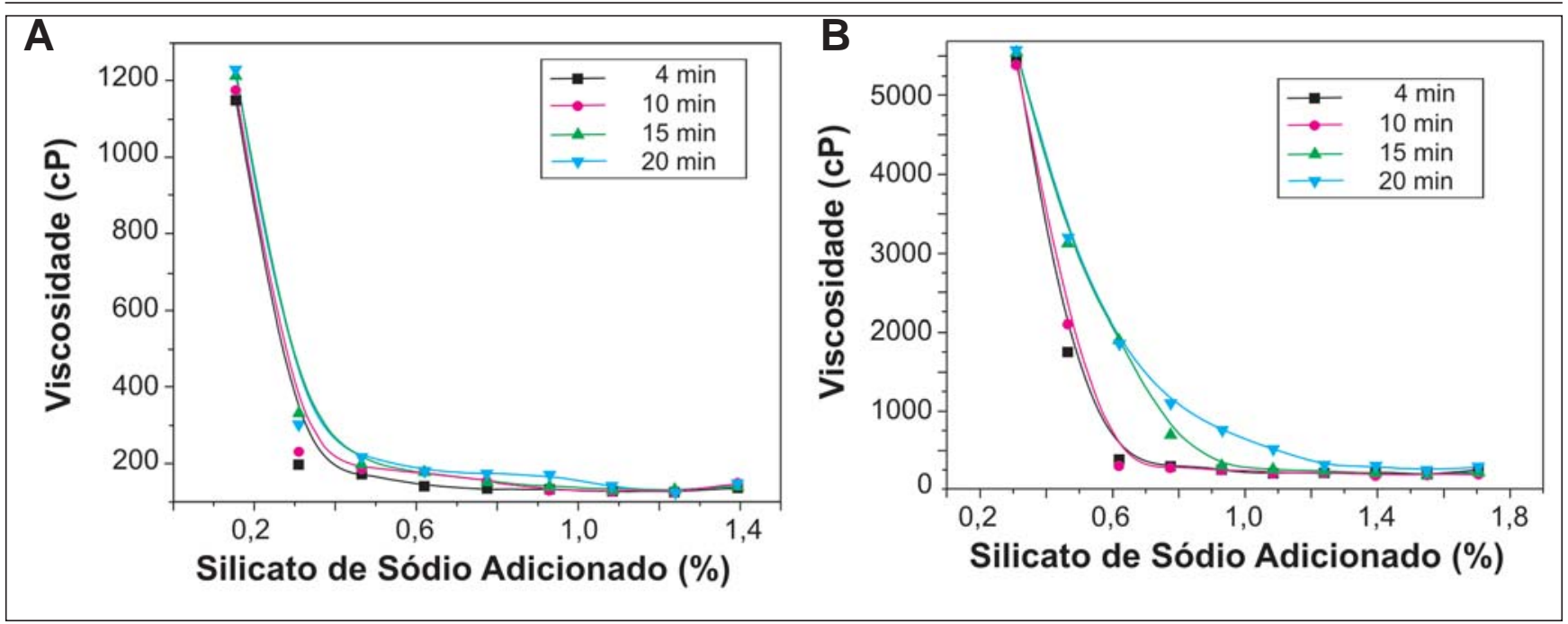

Figura 5 - Variação das curvas de defloculação com o tempo de moagem: A) TB2; B) TPátio.

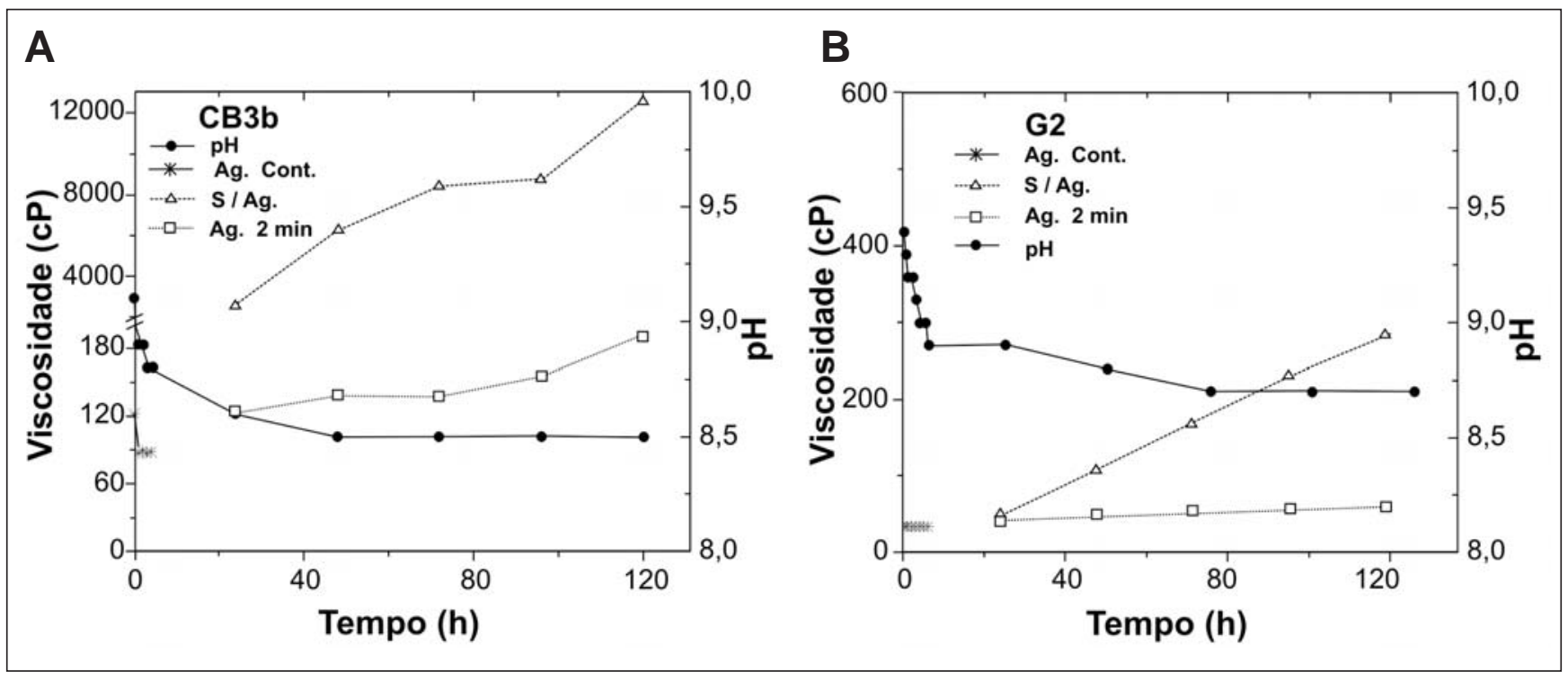

Figura 6 - Variação da viscosidade e pH com o tempo de preparo da barbotina: (a) CB3b; (b) G2. O eixo da viscosidade está em escala diferente nos dois gráficos. Ag. Cont.= agitação contínua; S/ Ag.= sem agitação; Ag. 2 min= agitação por 2 minutos; h = horas.

2 minutos, a viscosidade voltou a diminuir, não para os valores iniciais, mas para valores próximos. $\mathrm{O}$ pH de todas as amostras diminuiu com o passar do tempo, não apresentando variação entre a amostra em repouso e a mesma agitada por 2 minutos. A Figura 6 traz os resultados obtidos para as amostras CB3b e G2. Os gráficos, para as amostras CB3c e G1, não apresentados, são semelhantes ao da CB3b e o da amostra CB3a é semelhante ao da G2.

Ocorreu em todas as amostras o fenômeno de aumento da viscosidade com o tempo de preparo da barbotina, conhecido como envelhecimento, isto se deve ao rompimento dos aglomerados em partículas menores, diminuindo a relação entre o conteúdo de defloculante e a área superficial (Barba et alii, 1997).

\section{Conclusões}

A reologia varia com a composição mineralógica dos estratos. Tal composição, por sua vez, é influenciada por sua disposição espacial. Em consonância com a literatura, observou-se que as variações mineralógicas são mais evidentes na direção vertical. As amostras com maiores teores de carbonato encontram-se posicionadas no topo estratigráfico da Formação Corumbataí. A presença de carbonatos fez com que o conteúdo de silicato de sódio necessário para a defloculação fosse mais alto do que nas demais amostras, provenientes das outras minas em estudo.

Com exceção do litotipo altamente lixiviado coletado na bancada do topo da mina Tute (TB4), todos os demais litotipos da Formação Corumbataí (nas minas estudadas) deflocu- 
laram bem e tanto a quantidade de defloculante adicionada como as viscosidades são condizentes com os valores usados pela indústria cerâmica. A concentração crítica dos sólidos não é alta, mas o valor de $66 \%$ em peso encontrado é economicamente viável para a produção de placas cerâmicas. As amostras provenientes das minas Cruzeiro e Granusso apresentam maior teor relativo de argilominerais, quartzo e feldspatos e menor teor de carbonatos, o que pode explicar os melhores desempenhos frente à defloculação. Novos estudos serão realizados buscando determinar como o desequilíbrio de cargas nos argilominerais (quando alterados) pode afetar as propriedades reológicas. Verificou-se que as amostras onde se detectou a presença de matéria orgânica apresentaram menores valores de viscosidade (inferiores a $100 \mathrm{cP}$ quando defloculadas), dado que condiz com a literatura pertinente.

As barbotinas dos argilitos estudados da Fm. Corumbataí apresentaram o fenômeno de envelhecimento, porém a magnitude desse fenômeno é pequena, não inviabilizando a sua utilização.

Assim, pode-se dizer que os estratos que apresentarão, frente ao processo de moagem via úmida, melhores resultados serão os que contêm litotipos livres de alteração supérgena e/ou com teores de carbonato mais baixos. Por outro lado, mesmo o litotipo intemperizado pode ser adicionado à massa cerâmica (“blendagem”) sem prejuízo importante à fluidez da massa, fato este comprovado pelos resultados de TPátio, que contém aproximadamente 15\% desse litotipo.

\section{Agradecimentos}

Os autores agradecem à FAPESP pelo auxílio financeiro através projeto de pesquisa 03/01123-7 e ao CNPq e CAPES pela concessão de bolsas de iniciação científica e doutorado.

\section{Referências bibliográficas}

AMORÓS, J.L. et alii. La operación de prensado en la fabricación de pavimentos por monococción: I. influencia de la naturaleza del polvo de prensas sobre las propiedades de las piezas en crudo. Bol. Soc. Esp. Cer. Vid., v.27, n.5, p. 273-282, 1988.

AMORÓS, J.L. et alii. La operación de prensado en la fabricación de pavimentos por monococción: II. influencia de la naturaleza del polvo de prensas sobre las propiedades de las piezas en cocido. Bol. Soc. Esp. Cer. Vid., v.29, n.3, p. 151158, 1990.

BARBA, A. et alii. Materias primas para la fabricación de suportes de baldosas cerámicas. Castellón, Espanha: Castañeda, 1997. 292p.

CHRISTOFOLETTI, S.R. Um modelo de classificação geológico-tecnológica das argilas da Formação Corumbataí utilizadas nas indústrias do Pólo Cerâmico de Santa Gertrudes. Rio Claro: Instituto de Geociências e Ciências Exatas, Universidade Estadual Paulista, 2003. (Tese de Doutorado em Geologia Regional).

COUTINHO JUNIOR, T. A. Estudo da reologia das argilas da mina Granusso no município de Santa Gertrudes/SP, visando à formulação de massas cerâmicas para a fabricação de pisos e revestimentos pelo processo via úmida. Rio Claro: Instituto de Geociências e Ciências Exatas, Universidade Estadual Paulista, 2005. (Dissertação de Mestrado em Geologia Regional).

KRAUSKOPF, K. Introdução à geoquímica. São Paulo: Editora da Universidade de São Paulo - Editora Polígono, 1972. v. 2. 311p.

LANDIM, P.M.B. O Grupo Passa Dois na Bacia do Rio Corumbataí (SP). São Paulo: Divisão Geologia e Mineralogia/DNPM. 1970. 103p. (Boletim 252).

NORTON, F.H. Introdução à tecnologia cerâmica. São Paulo: Edgard Blücher, 1979. 323p.

PRADO, A.C.A. et alii. Rheology of clays from the Corumbataí Formation and their application in porcelain tile production. In: QUALICER, 9, 2006. Castellón, Espanha. Anais... Castellón: Logui Impresión, 2006. v.3, p. 245-249.

ROVERI, C.D. Caracterização geológica das minas Tute e Granusso (região de Rio Claro - SP) visando à fabricação de revestimentos cerâmicos via úmida. Rio Claro: Instituto de Geociências e Ciências Exatas, Universidade Estadual Paulista, 2005. (Trabalho de Conclusão do Curso de Graduação em Geologia).

ROVERI, C.D. et alii. Compositional variation of the Corumbataí Formation and mine locations in the ceramic pole of Santa Gertrudes-Brazil. In: QUALICER, 9. Castellón, Espanha. Anais... Castellón: Logui Impresión, 2006. v.3, p. 185-188.

ROVERI, C.D., ZANARDO, A. Estudo do comportamento reológico de argilas provenientes da Formação Corumbataí (região de Rio Claro/SP): resultados preliminares. In: SIMP. GEOL. DO SUDESTE, 8. São Pedro. Anais... Rio Claro: Divisa Editora, 2003. p. 188.

SOUZA SANTOS, P. Propriedades coloidais do sistema argila + água. In: Ciência e tecnologia de argilas. 2 ed. São Paulo: Edgard Blücher, 1989. v.1., p. 92-125. 408 p.

THOMAZELLA, H.R. et alii. Utilização da Formação Corumbataí em processo de fabricação cerâmica via úmida. In: CONGRESSO BRASILEIRO DE CERÂMICA, 44. Anais... São Paulo: Microservice Tecnologia Digital, 2000. 1 CD-ROM.

ZANARDO, A. Pesquisa geológica e de matérias-primas cerâmicas do centro nordeste do Estado de São Paulo e vizinhanças: sistematização crítica da produção técnico-científica. Rio Claro: Instituto de Geociências e Ciências Exatas, Universidade Estadual Paulista, 2003. (Tese de Livre Docência).

Artigo recebido em 15/03/2007 e aprovado em 04/07/2007.

\section{Rem - Revista Escola de Minas - www.rem.com.br}

